\title{
Sudden death in eating disorders
}

\author{
This article was published in the following Dove Press journal: \\ Vascular Health and Risk Management \\ 14 February 2012 \\ Number of times this article has been viewed
}

\section{Beatriz Jáuregui-Garrido' Ignacio Jáuregui-Lobera ${ }^{2,3}$}

'Department of Cardiology, University Hospital Virgen del Rocío, ${ }^{2}$ Behavioral Sciences Institute, ${ }^{3} \mathrm{Pablo}$ de Olavide University, Seville, Spain
Correspondence: Ignacio Jáuregui-Lobera Virgen del Monte 3I, Seville 4I 0 I I, Spain Tel +34954280789

Fax +34954278167

Email ignacio-ja@telefonica.net
Abstract: Eating disorders are usually associated with an increased risk of premature death with a wide range of rates and causes of mortality. "Sudden death" has been defined as the abrupt and unexpected occurrence of fatality for which no satisfactory explanation of the cause can be ascertained. In many cases of sudden death, autopsies do not clarify the main cause. Cardiovascular complications are usually involved in these deaths. The purpose of this review was to report an update of the existing literature data on the main findings with respect to sudden death in eating disorders by means of a search conducted in PubMed. The most relevant conclusion of this review seems to be that the main causes of sudden death in eating disorders are those related to cardiovascular complications. The predictive value of the increased QT interval dispersion as a marker of sudden acute ventricular arrhythmia and death has been demonstrated. Eating disorder patients with severe cardiovascular symptoms should be hospitalized. In general, with respect to sudden death in eating disorders, some findings (eg, long-term eating disorders, chronic hypokalemia, chronically low plasma albumin, and QT intervals $>600$ milliseconds) must be taken into account, and it must be highlighted that during refeeding, the adverse effects of hypophosphatemia include cardiac failure. Monitoring vital signs and performing electrocardiograms and serial measurements of plasma potassium are relevant during the treatment of eating disorder patients.

Keywords: sudden death, cardiovascular complications, refeeding syndrome, QT interval, hypokalemia

\section{Introduction}

Medical manifestations of eating disorders (EDs) are not mere complications but relevant signs and symptoms of these pathologies. ${ }^{1}$ Nevertheless, current classifications (ie, International Classification of Diseases, Diagnostic and Statistical Manual of Mental Disorders: Fourth Edition; Text Revision) do not pay special attention to the medical facets of anorexia and bulimia nervosa. ${ }^{2,3}$ Manifestations usually result from starvation or from the behaviors adopted to induce it. ${ }^{1}$ In the case of anorexia nervosa, although many of these medical manifestations improve with nutritional rehabilitation and recovery from the ED, some are potentially irreversible. ${ }^{4}$ Cardiovascular disturbances may have detrimental consequences and it seems they are present in the early stages of anorexia nervosa among adolescents. ${ }^{5}$ Refeeding syndrome can result from the use of oral, enteral, or parenteral nutrition in malnourished patients. ${ }^{4}$ In affected children and adolescents, growth failure and short stature are possible as well as osteopenia and osteoporosis. ${ }^{6-8}$ Finally, different structural and functional 
brain changes have been reported among ED patients..$^{9,10}$ Similar manifestations can be observed in bulimia nervosa, although the main signs and symptoms are usually related to the gastrointestinal tract (eg, dental erosion, parotid and salivary gland enlargement, esophagitis, vomiting, gastric rupture, constipation, etc). ${ }^{11}$

EDs are usually associated with an increased risk of premature death with a wide range of rates and causes of mortality. ${ }^{12}$ Inanition, electrolyte disturbances, dehydration, suicide, and alcoholism, among others, have been reported as causes of mortality in EDs. ${ }^{12}$ Standardized mortality ratios for anorexia nervosa vary from $1.36 \%$ to $20 \%$ with a narrower range for bulimia nervosa ( $1 \%$ to $3 \%) .{ }^{12-14}$ Patients with anorexia nervosa are more likely to make a serious suicide attempt, with a higher expectation of dying and an increased risk of severity. It must be noted that clinical markers of the severity of EDs seem associated with the seriousness of such attempts. ${ }^{15}$

"Sudden death" has been defined as the abrupt and unexpected occurrence of fatality for which no satisfactory explanation of the cause can be ascertained. ${ }^{14}$ It must be noted that the mechanism of death in EDs, particularly in anorexia nervosa, is poorly understood. In many cases, death is attributed to complications (which are not always well defined) and in cases of sudden deaths autopsies do not always clarify the main cause of death. Cardiovascular complications are usually involved in these deaths. ${ }^{14,16-18}$ Although a variety of somatic alterations, cardiac arrhythmia, and acute circulatory failure have been reported in cases of sudden death among ED patients, in many cases the exact cause is not specified. ${ }^{14}$

The aim of this review is to describe the causes of sudden death in patients with ED by means of a literature search of PubMed. ${ }^{19}$

\section{Materials and methods}

A search of the literature on PubMed was undertaken using the following search terms: "sudden death and eating disorders," "sudden death and anorexia nervosa," "sudden death and bulimia nervosa," and "sudden death and eating disorders and not otherwise specified." A total of 144 articles was obtained, excluding those not specifically focused on anorexia and/or bulimia nervosa as well as on the clear relationship between specific EDs and sudden deaths. Articles without an abstract were also excluded. The search for "sudden death and eating disorders" yielded 76 articles, a total of 60 articles was obtained when "sudden death and anorexia nervosa" was entered, and eight articles were found by entering "sudden death and bulimia nervosa." The search for "sudden death and eating disorders and not otherwise specified" yielded no results.

\section{Results \\ Cardiovascular complications and sudden death}

At least one-third of all deaths in patients with anorexia nervosa are estimated to be due to cardiac causes, mainly sudden death. ${ }^{14,16,20}$ Cardiovascular complications are common, and they have been reported in up to $80 \%$ of the cases; up to $10 \%$ of these complications were mainly bradycardia, hypotension, arrhythmias, repolarization abnormalities, and sudden death. ${ }^{14,16,17,21-23}$ It must be noted that food restriction can lead to increased vagal tone, bradycardia, orthostatic hypotension, syncope, arrhythmias, congestive heart failure, and sudden death. ${ }^{24}$ Bradycardia presents particularly during the night but neither mean QT nor corrected mean QT length over 24-hour monitoring seem to be different compared with controls. ${ }^{25}$

With respect to QT abnormalities, QT interval is a measure of myocardial repolarization and its length is associated with life-threatening ventricular tachycardia. Thus, a prolonged QT interval is a biomarker for ventricular tachyarrhythmia and a risk factor for sudden death. ${ }^{17}$ In EDs, QT interval abnormalities have been studied as a marker of sudden death and also to assess the effect of refeeding. It has been proposed that sudden deaths are a result of cardiac arrhythmias for which a long QT interval on the electrocardiogram would be a marker. The necropsy and clinical findings in three cases of sudden death reported by Isner et al provided evidence that sudden death in anorexia nervosa, like sudden death in liquidprotein dieting, might result from ventricular tachyarrhythmia related to QT interval prolongation. ${ }^{16,26}$ Nevertheless, the QT interval seems to have a poor predictive value for the recognition of patients who are at particular risk of sudden death. Only QT intervals $>600$ milliseconds are clearly associated with a significant risk of sudden death, but few ED patients usually have such long QT intervals. ${ }^{27}$ Considering the QT dispersion, an increase of the QT interval dispersion represents regional differences in myocardial excitability recovery and may lead to an increased arrhythmogenic substrate, with a higher risk for clinically significant ventricular arrhythmia and sudden death. In this case, the predictive value of the increased QT interval dispersion as a marker of sudden acute ventricular arrhythmia or death has been demonstrated. ${ }^{16,22}$ Both prolonged QT interval and increased QT interval dispersion tend to normalize after refeeding, along with heart rate and heart-rate variability. ${ }^{5,28}$ 
ED patients may show varying degrees of dehydration; sodium and chloride depletion, particularly in patients who vomit; potassium deficiency (in patients who abuse laxatives); and weaknesses of chloride, sodium, and potassium in patients using diuretics, with different depletions depending on the substance used. ${ }^{29}$ In the case of hypokalemia, repolarization abnormalities (prolonged and depressed QT interval and decreased height of the T-wave) are usually found. Nevertheless, there is no correlation between potassium levels and specific signs in the electrocardiogram. In any case, cardiac or respiratory arrest is the most frequent cause of sudden death. Among the different findings, T-wave flattening or inversion is present with potassium levels of 3.0-3.8 $\mathrm{mEq} / \mathrm{L}$ and a long QT interval, prominent $\mathrm{U}$-wave, depression of the ST segment, and ventricular extrasystoles can be found with potassium levels of $2.3-3.0 \mathrm{mEq} / \mathrm{L}$. In addition, torsades de pointes and ventricular fibrillation may be present with potassium levels $<2.3 \mathrm{mEq} / \mathrm{L}$. Again, QT prolongation and ventricular arrhythmia may develop in the setting of severe hypokalemia, exposing patients to high risk of sudden cardiac event. ${ }^{30}$

\section{Tako tsubo cardiomyopathy}

Tako tsubo syndrome (apical ballooning syndrome), first described in Japan in 1991, ${ }^{31}$ is a reversible cardiomyopathy precipitated by acute and severe emotional stress mainly observed in postmenopausal women. It has been explained by catecholamine-mediated myocardial stunning, due to the fact that an emotional or physical stressor usually precedes the syndrome. ${ }^{32-35}$ In the context of EDs, this syndrome can be a serious complication in young females with anorexia nervosa and acute symptoms, including cardiogenic shock and ventricular arrhythmias, can be severe and death may result. ${ }^{33}$ Some cases of this syndrome following hypoglycemia (which increases plasma catecholamine levels) have been described in anorectic patients. ${ }^{33,36}$ as well as a case complicated by several syncopes due to recurrent episodes of torsades de pointes. In this regard, the combination of tako tsubo cardiomyopathy with a condition associated with the prolongation of QT and/or with an increase of QT dispersion, such as anorexia nervosa, makes the prognosis of this disease much more severe than usual. ${ }^{37}$

Besides QT abnormalities, other possible causes of death among ED patients have been described. For example, in a case of sudden death in anorexia nervosa, some unexpected autopsy findings were reported by Derman and Szabo. ${ }^{18}$ The postmortem examination revealed multiple bilateral pulmonary thromboembolisms and bilateral calf vein thrombosis.
In another study, a 39-year-old woman with longstanding anorexia nervosa suffered a myocardial infarction of the inferior wall during refeeding. The authors suggested that anorexia nervosa does not "protect" against coronary atherosclerosis and that some cases of sudden death could be related to myocardial ischemia. ${ }^{38}$ However, another case of acute myocardial infarction has recently been reported in a woman with anorexia nervosa. ${ }^{39}$

The medicolegal investigation into the causes of unexpected deaths of ED patients may find a number of risk factors whose interplay may result in a cardiovascular catastrophe. In this regard, heart atrophy, bleeding, fragmentation and contraction bands of the myofibrils, and disproportion between the size of the mitral valve and the atrophic ventricular wall have been described. ${ }^{40}$ Lipofuscin accumulations in myocardium have also been reported. ${ }^{41}$ Another mechanism of cardiovascular mortality and sudden death among ED patients is the alteration in sympathovagal balance and an increased vagal tone in a young woman with anorexia nervosa has been described. ${ }^{42}$

Table 1 summarizes the main findings about sudden death related to cardiovascular complications.

\section{Hypoglycemia and sudden death}

The presence of hypoglycemia is well-known in starvation, including in cases of anorexia nervosa. ${ }^{43}$ Previous studies have described severe hypoglycemia in anorexia nervosa as having no symptoms. ${ }^{44-46}$ Hypoglycemic coma is an unusual complication in anorexia nervosa, which has been described in some cases reflecting severe malnutrition and indicating a poor and possibly fatal prognosis..$^{47,48}$ It has been suggested that hypoglycemia associated with anorexia nervosa is a serious risk factor, especially when body weight falls below $30 \mathrm{~kg}$, but in men it may occur at a higher total body weight. ${ }^{49-51}$ Sudden death related to hypoglycemia has been reported in ED patients, usually associated with other complications, such as pulmonary edema, cerebral hemorrhage (Weber's syndrome) or coincident with acute exacerbation of liver injury induced by oral intake of nutrients. ${ }^{52-54}$

\section{Gastric dilatation and gastric rupture}

EDs usually cause gastrointestinal disturbances, such as decreased gastric motility and delayed gastric emptying, which may rarely lead to acute gastric dilatation. ${ }^{55}$ Acute gastric dilatation is considered a surgical emergency as gastric necrosis, perforation, shock, and death can occur if treatment is delayed. ${ }^{56-58}$ There are different causes of 
Table I Sudden death related to cardiovascular complications: main findings

- At least one-third of all deaths in patients with anorexia nervosa are estimated to be due to cardiac causes, mainly sudden death $14,15,18$

- Cardiovascular complications are common and they have been reported in up to $80 \%$ of patients with anorexia nervosa, mainly in the form of bradycardia, hypotension, arrhythmias, repolarization abnormalities, and sudden death by up to $10 \%$ of the cases with these types of cardiovascular disturbances ${ }^{14-16,19-21}$

- Food restriction can lead to increased vagal tone, bradycardia, orthostatic hypotension, syncope, arrhythmias, congestive heart failure, and sudden death ${ }^{22}$

- Duration of the QT interval of the electrocardiogram is a function of the heart rate and a prolonged QT interval is a biomarker for ventricular tachyarrhythmia and a risk factor for sudden death ${ }^{15,16,79}$

- The measurement of QT interval has a poor predictive value for the recognition of patients who are at particular risk of sudden death. A measured QT interval of $>600$ milliseconds is associated with a significant risk of sudden death, but few patients usually have such long QT intervals ${ }^{24}$

- In refeeding syndrome, congestive heart failure results from decreased ventricular mass and myofibrillar atrophy, causing decreased stroke volume and reduced capacity of the cardiovascular system ${ }^{4}$

- Some cases of myocardial infarction have been described in eating disorder patients. This complication increases the risk of sudden death among those patients ${ }^{35,36}$

- Another mechanism of cardiovascular mortality and sudden death among eating disorder patients is the alteration in sympathovagal balance ${ }^{39}$

acute gastric distension (eg, refeeding after starvation, diabetes mellitus, tumors, gastric volvulus, gastroduodenal tuberculosis, gastroduodenal Crohn's disease), but patients with EDs, approximately $60 \%$ of whom will have gastric dysmotility, are at increased risk for acute gastric dilatation due to decreased gastric motility, increased gastric capacity, and decreased gastric emptying. ${ }^{59,60}$

Besides some reversible ED cases with gastric dilatation and gastric rupture, several cases of death have been described. In 2008, Watanabe et $\mathrm{al}^{58}$ reported the first autopsy case of fatal gastric dilatation without rupture. Severe congestion was observed in the intestine and cecum, suggesting that bulimia nervosa together with anorexia nervosa resulted in rapid gastric dilatation. The authors suggested that the cause of death was acute circulatory failure from hypovolemic shock that occurred following compression of the inferior vena cava and superior mesenteric vein, and loss of circulatory volume to the third space. Fatal gastric rupture due to a bulimic attack was discovered after death in a young woman suffering from anorexia nervosa. Autopsy revealed an acute gastric dilatation and rupture without commonly observed ischemic damage of gastric wall structures. In this case, the death as a consequence of neurogenic shock accounted for all the results of gross examination and histologic analyses. ${ }^{61} \mathrm{With}$ respect to the acute gastric dilatation, a case of cardiac arrest has been also described recently in a case of binge ED. ${ }^{62}$ Not every instance of gastric dilatation in EDs is preceded by a history of delayed gastric emptying as was shown in a recent study. ${ }^{63}$ In other cases, even a single binge episode can cause a gastric dilatation. ${ }^{64,65}$ Gastric dilatation associated with superior mesenteric artery syndrome has been also described in EDs, ${ }^{66-68}$ as well as gastric dilatation associated with acute pancreatitis. ${ }^{69}$
The other severe presentation of gastric dilatation is gastric infarction, which has been reported in several ED cases, sometimes with a fatal outcome. . $^{7,71}$

\section{Cardiovascular risk during refeeding syndrome}

"Refeeding syndrome" can be defined as the potentially fatal shift in fluids and electrolytes that may occur in malnourished patients receiving artificial refeeding. These shifts result from hormonal and metabolic changes and may cause serious clinical complications. The hallmark biochemical feature of refeeding syndrome is hypophosphatemia. In addition, other abnormalities can be found (eg, hypokalemia, hypomagnesemia). ${ }^{72}$ The change to anabolism, which occurs during refeeding, causes an increase in insulin secretion and, consequently, potassium is taken into cells. As a result, disturbances in the electrochemical membrane potential can result in arrhythmias and cardiac arrest. ${ }^{72}$ Hypomagnesemia also affects membrane potential leading to cardiac complications. Besides the changes in potassium and magnesium levels, in refeeding syndrome phosphorus depletion occurs, which in turns leads to widespread dysfunction of cellular processes affecting almost every physiological system. Moreover, the introduction of carbohydrates to a diet leads to a rapid decrease in renal excretion of sodium and water. In this environment, patients may rapidly develop fluid overload with congestive cardiac failure, pulmonary edema, and cardiac arrhythmia. ${ }^{72,73}$

\section{Other factors involved in sudden death among ED patients}

Some unusual deaths related to abnormal eating patterns (polyphagia) have been communicated with asphyxia as an unusual etiology. A sudden subdiaphragmatic viscus 
expansion, with resultant lung volume displacement and impediment of venous return from the lower half of the body, and infraglottic asphyxia have been noted as the main causes of these deaths. ${ }^{74}$

In a study among severely malnourished patients, diaphragmatic contractility was severely depressed initially. This situation may cause acute respiratory distress and sudden death but is normally reversible with an adequate refeeding. ${ }^{75}$

In addition to well-known electrolyte disturbances, anorexia nervosa nay be complicated by severe hypophosphatemia, which can cause muscle weakness and bulbar muscle dysfunction, resulting in aspiration pneumonia and cardiorespiratory arrest. ${ }^{76}$

Abuse of emetics such as ipecac can result in irreversible and potentially fatal cardiomyopathies. ${ }^{77}$ Friedman described a patient with anorexia nervosa who developed a fatal cardiomyopathy due to ipecac intoxication. Autopsy revealed pathological changes in the heart and skeletal muscles. ${ }^{78}$ Ipecac abuse occurs predominantly among adolescent and young adult females who are either experimenting with purging behaviors or have an ED. Death can be the result, which is normally of cardiac origin (myocarditis with arrhythmias). Other causes of death with the use of ipecac are myositis, gastroesophageal pathology (including rupture), and metabolic abnormalities. ${ }^{79}$

In a case of longstanding bulimia nervosa subsequent to anorexia nervosa, death was caused by pneumonia and sepsis. Autopsy revealed chronic interstitial nephritis, proximal tubular swelling, and diffuse glomerular sclerosis, suggesting chronic glomerular injury associated with longterm binging/purging. ${ }^{80}$ With respect to renal function, acute renal failure induced by the presence of rhabdomyolysis has been reported to have been caused by refeeding-induced hypophosphatemia. ${ }^{81}$

Postmortem studies on the brain of a patient who died of acute anorexia nervosa showed a slim neuron type with one extremely long basal dendritic field. In the neurons, the ramification pattern of single basal dendritic fields was found to be reduced and changes in the spine morphology, as well as reduction in spine density, were observed. The authors concluded that all anorexia nervosa deaths should be reported together with descriptions of causes and cerebral alterations. ${ }^{82}$

Different severe acute inflammations such as pneumonia and peritonitis have been described in patients with anorexia nervosa. ${ }^{83}$ In one case, these inflammations and a severe electrolyte imbalance caused a cardiorespiratory arrest which required the patient to be resuscitated. In another case, a sepsis with multiple organ dysfunction syndrome caused the death of the patient. ${ }^{83}$ Generally, prolonged electrolyte disturbances in anorexia nervosa, catabolism, and insufficient immunity are the main factors for developing an acute inflammation, as well as some other complications, such as cardiorespiratory failure, nosocomial infection, and sepsis with multiple organ failure..$^{83}$

\section{Discussion}

Investigations of sudden deaths by forensic pathologists have usually mentioned long QT syndrome as the main explanation. In addition, the absence of abnormal findings at postmortem examinations has highlighted the heritable nature of these sudden deaths. In many instances, a "negative" autopsy is long QT syndrome and potential causes of sudden death can have a genetic basis in addition to other disturbances. ${ }^{84}$

EDs, particularly anorexia nervosa, are life-threatening diseases with a high risk of death due to cardiovascular disturbances, which can also be present during refeeding. ${ }^{85}$ Cardiovascular complications - including bradycardia, QT interval prolongation, orthostatic hypotension, increased vagal tone, mitral valve prolapse (as a consequence of weight loss with an associated reduction in left ventricle mass, resulting in a relatively large mitral valve), possible alterations in myocardial contractility, and reduction in left ventricular wall thickness, among others - are present in the early stages. Some of these alterations can lead to sudden death and a model of clinical monitoring of cardiovascular system should be developed carefully. ${ }^{86}$ In fact, ED patients with severe cardiovascular alterations should be admitted to the hospital in order to monitor their cardiac function and to ensure that they gain weight gradually. ${ }^{87}$ This is important in purging-type ED, as purging may increase the risk of hypokalemia and subsequent cardiac dysrhythmias, and selfinduced vomiting increases the risk of additional complications. ${ }^{88}$ In fact, QT prolongation and ventricular arrhythmia may develop in the setting of severe hypokalemia, exposing patients to high risk of sudden cardiac event..$^{30,89}$

It must be noted that risk of death is clearly linked to QT prolongation, mainly due to hypokalemia or to a starvationderived anatomical remodeling of the heart. The principal risk factors seem to be duration of illness ( $>10$ years), chronic hypokalemia, plasmatic albumin chronically $<3.6 \mathrm{~g} / 100 \mathrm{~mL}$ and absolute QT $\geq 600$ milliseconds. ${ }^{90}$

Despite some conflicting results (mainly for methodological reasons) about QT interval alterations, prolongation of the 
QT is usually associated with sudden ventricular arrhythmias and death. Nevertheless, the main cardiovascular findings among patients with EDs are reversible by means of appropriate refeeding. As a result of this refeeding, increase in cardiac dimensions, ventricular mass, and cardiac output are reached. 5,17,28,91,92 It must be noted that left ventricular dysfunction, usually present as an asymptomatic finding, must be taken into account despite the fact that most cases are reversible after renutrition in hospital. ${ }^{93}$

With respect to the above-mentioned causes of sudden death, many of them (eg, protein-calorie malnutrition, ipecac toxicity, deficiencies of phosphorus and magnesium) cause the sudden death by means of congestive heart failure. ${ }^{94}$

Hypoglycemia, generally asymptomatic, is a usual finding among ED patients. Severe cases (plasma glucose levels as low as $18-20 \mathrm{mg} / \mathrm{dL}$ ), including coma, were first described in the 1980s and since then the pathogenesis remains unclear, some etiological factors, such as excessive exercise, depletion of glycogen, gluconeogenesis failure, or some disturbances with respect to glucagon secretion, having been pointed out. Severe hypoglycemia is related to poor prognosis in ED patients. ${ }^{47,49,95}$ As mentioned, the risk of hypoglycemia-related sudden death has been reported in ED patients and is usually associated with other complications.

The pathophysiology of gastric dysfunction in ED is poorly understood. Several mechanisms, such as gastrointestinal smooth muscle atrophy, diminished release of cholecystokinin, abnormalities in the autonomic nervous system, and gastric rhythm abnormalities, have been considered. ${ }^{55}$ Acute gastric dilatation is uncommon in clinical practice in the field of EDs. Gastric infarction as a complication of acute gastric dilatation is an unusual associated circumstance. Nevertheless, both may be present in EDs, leading to perforation and death. ${ }^{71}$

It must be noted that the main results about sudden death in EDs are those related to anorexia nervosa. In the case of bulimia nervosa, electrolyte disturbances are the main origin of sudden death by means of purging behaviors. With respect to EDs not otherwise specified, the search conducted yielded no results despite a recent study that has established that mortality rates for bulimia nervosa and EDs not otherwise specified seem to be similar. ${ }^{96}$

\section{Conclusion}

The most relevant conclusion of this review seems to be that the main causes of sudden death in EDs are those related to cardiovascular complications. The predictive value of the increased QT interval dispersion as a marker of sudden acute ventricular arrhythmia and death has been demonstrated. ${ }^{16,22}$ Purging behaviors may increase the risk of hypokalemia and subsequent cardiac dysrhythmias. Thus, monitoring vital signs and performing electrocardiograms and serial measurements of plasma potassium are relevant. ED patients with severe cardiovascular symptoms should be hospitalized. The presence of purging behaviors increases the cardiovascular risk. Medical problems associated with laxative abuse include electrolyte and acid/base changes that can involve the renal and cardiovascular systems and may become life threatening. The same applies to the use/abuse of emetics. ${ }^{97}$

Some findings (eg, long-term ED, chronic hypokalemia, chronically low plasmatic albumin, and QT intervals $>600$ milliseconds) must be especially taken into account. During refeeding, the adverse effects of hypophosphatemia include cardiac failure. Cardiac sequelae are secondary to and occur early in the cascade of events that arise during refeeding. ${ }^{4}$ A large number of ED patients have gastrointestinal dysmotility, so a complete medical exploration should be done in this regard. In fact, no ED patients should start any treatment without full medical and nutritional explorations.

\section{Disclosure}

The authors report no conflicts of interest in this work.

\section{References}

1. Birmingham CL, Beumont P. Medical Management of Eating Disorders. Cambridge: Cambridge University Press; 2004.

2. World Health Organization. International Classification of Diseases. Geneva: World Health Organization; 1992.

3. American Psychiatric Association. Diagnostic and Statistical Manual of Mental Disorders: Fourth Edition; Text Revision. Washington DC: American Psychiatric Association; 2000.

4. Katzman DK. Medical complications in adolescents with anorexia nervosa: a review of the literature. Int J Eat Disord. 2005;Suppl 37: S52-S59.

5. Mont L, Castro J, Herreros B, et al. Reversibility of cardiac abnormalities in adolescents with anorexia nerovsa after weight recovery. $J \mathrm{Am}$ Acad Child Adolesc Psychiatry. 2003;42(7):808-813.

6. DanzigerY, Mukamel M, Zeharia A, Dinari G, Mimouni M. Stunting of growth in anorexia nervosa during the prepubertal and pubertal period. Isr J Med Sci. 1994;30(8):581-584.

7. Nussbaum M, Baird D, Sonnenblick M, Cowan K, Shenker IR. Short stature in anorexia nervosa patients. J Adolesc Health Care. 1985;6(6): 453-455.

8. Bachrach LK, Guido D, Katzman D, Litt IF, Marcus R. Decreased bone density in adolescent girls with anorexia nervosa. Pediatrics. 1990; $86(3): 440-447$.

9. Jáuregui-Lobera I. Neuroimaging in eating disorders. Neuropsychiatr Dis Treat. 2011;7:577-584.

10. Jáuregui-Lobera I. Electroencephalograpy in eating disorders. Neuropsychiatr Dis Treat. 2011. In press.

11. Lionetti E, La Rosa M, Cavallo L, Francavilla R. Gastrointestinal aspects of bulimia nervosa. In: Hay P, editor. New Insights into the Prevention and Treatment of Bulimia Nervosa. Rijeca, Croatia: In Tech; 2011.

12. Herzog DB, Greenwood DN, Dorer DJ, et al. Mortality in eating disorders: a descriptive study. Int J Eat Disord. 2000;28(1):20-26. 
13. Emborg C. Mortality and causes of death in eating disorders in Denmark 1970-1993: a case register study. Int J Eat Disord. 1999;25(3): 243-251.

14. Neumärker KJ. Mortality and sudden death in anorexia nervosa. Int $J$ Eat Disord. 1997;21(3):205-212.

15. Guillaume S, Jaussent I, Olié E, et al. Characteristics of suicide attempts in anorexia and bulimia nervosa: a case-control study. PLoS One. 2011; 6(8):e23578.

16. Isner JM, Roberts WC, Heymsfield SB, Yager J. Anorexia nervosa and sudden death. Ann Intern Med. 1985;102(1):49-52.

17. Cooke RA, Chambers JB. Anorexia nervosa and the heart. Br J Hosp Med. 1995;54(7):313-317.

18. Derman T, Szabo CP. Why do individuals with anorexia die? A case of sudden death. Int J Eat Disord. 2006;39(3):260-262.

19. PubMed.gov [database on the Internet]. Bethesda, MD: National Center for Biotechnology Information, US Library of Medicine; nd. Available from: http://www.ncbi.nlm.nih.gov/pubmed/. Accessed January 17, 2012.

20. Sharp CW, Freeman CP. The medical complications of anorexia nervosa. Br J Psychiatry. 1993;162:452-462.

21. de Simone G, Scalfi L, Galderisi M, et al. Cardiac abnormalities in young women with anorexia nervosa. Br Heart J. 1994;71(3):287-292.

22. Harris JP, Kreipe RE, Rossbach CN. QT prolongation by isoproterenol in anorexia nervosa. J Adolesc Health. 1993;14(5):390-393.

23. St John Sutton M, Plappert T, Crosby L, Douglas P, Mullen J, Reichek N. Effects of reduced left ventricular mass on chamber architecture, load, and function: a study of anorexia nervosa. Circulation. 1985;72(5):991-1000

24. Casiero D, Frishman WH. Cardiovascular complications of eating disorders. Cardiol Rev. 2006;14(5):227-231.

25. Roche F, Estour B, Kadem M, et al. Alteration of the QT rate dependence in anorexia nervosa. Pacing Clin Electrophysiol. 2004;27(8):1099-1104.

26. Duraković Z, Korsić M, Gregurić S, Zimonja-Krisković J. Corrected Q-T interval in the electrocardiogram in patients with anorexia nervosa. Lijec Vjesn. 1989;111(11):374-376. Croatian.

27. Jackman WM, Friday KJ, Anderson JL, Aliot EM, Clark M, Lazzara R. The long QT syndromes: a critical review, new clinical observations and a unifying hypothesis. Prog Cardiovasc Dis. 1988;31(2):115-172.

28. Swenne I, Larsson PT. Heart risk associated with weight loss in anorexia nervosa and eating disorders: risk factors for QTc interval prolongation and dispersion. Acta Paediatr. 1999;88(3):304-309.

29. Jaúregui I. La imagen de una sociedad enferma. Anorexia, bulimia, atracones y obesidad. [The image of a sick society. Anorexia, bulimia, binge eating and obesity]. Barcelona: Grafema; 2006. Spanish.

30. Facchini M, Sala L, Malfatto G, Bragato R, Redaelli G, Invitti C. Low-K+ dependent QT prolongation and risk for ventricular arrhythmia in anorexia nervosa. Int J Cardiol. 2006;106(2):170-176.

31. Dote K, Sato H, Tateishi H, Uchida T, Ishihara M. Myocardial stunning due to simultaneous multivessel coronary spasms: a review of 5 cases J Cardiol. 1991;21(2):203-214. Japanese.

32. Akashi YJ, Goldstein DS, Barbaro G, Ueyama T. Takotsubo cardiomyopathy: a new form of acute, reversible heart failure. Circulation. 2008;118(25):2754-2762.

33. Volman MN, Ten Kate RW, Tukkie R. Tako Tsubo cardiomyopathy, presenting with cardiogenic shock in a 24-year-old patient with anorexia nervosa. Neth J Med. 2011;69(3):129-131.

34. Wittstein IS, Thiemann DR, Lima JA, et al. Neurohumoral features of myocardial stunning due to sudden emotional stress. $N$ Engl J Med. 2005;352(6):539-548.

35. Ako J, Sudhir K, Farouque HM, Honda Y, Fitzgerald PJ. Transient left ventricular dysfunction under severe stress: brain-heart relationship revisited. Am J Med. 2006;119(1):10-17.

36. Ohwada R, Hotta M, Kimura H, et al. Ampulla cardiomyopathy after hypoglycaemia in three young female patients with anorexia nervosa. Intern Med. 2005;44(3):228-233.

37. Rotondi F, Manganelli F, Lanzillo T, et al. Tako-tsubo cardiomyopathy complicated by recurrent torsade de pointes in a patient with anorexia nervosa. Inter Med. 2010;49(12):1133-1137.
38. García-Rubira JC, Hidalgo R, Gómez-Barrado JJ, Romero D, Cruz Fernández JM. Anorexia nervosa and myocardial infarction. Int $J$ Cardiol. 1994;45(2):138-140.

39. Abuzeid W, Glover C. Acute myocardial infarction and anorexia nervosa. Int J Eat Disord. 2011;44(5):473-476.

40. Rajs J, Rajs E, Lundman T. Unexpected death in patients suffering from eating disorders. A medico-legal study. Acta Psychiatr Scand. 1986; 74(6):587-596.

41. Missliwetz J, Ellinger A, Risser D. Sudden death caused by anorexia nervosa. Beitr Gerichtl Med. 1991;49:343-352. German.

42. Petretta M, Bonaduce D, Scalfi L, et al. Heart rate variability as a measure of autonomic nervous system function in anorexia nervosa. Clin Cardiol. 1997;20(3):219-224.

43. Marks V. Hypoglycaemia. 2. Other causes. Clin Endocrinol Metab. 1976;5(3):769-782.

44. Bartels ED. Studies on hypometabolism. I. Anorexia nervosa. Acta Med Scand. 1946;124:185-211.

45. Bliss EL, Branch CH. Anorexia Nervosa. New York: Hoeber; 1960. p. 103.

46. Bruckner WJ, Wies CH, Lavietes PH. Anorexia nervosa and pituitary cachexia. Am J Med Sci. 1938;196:663-673.

47. Rich LM, Caine MR, Findling JW, Shaker JL. Hypoglycemic coma in anorexia nervosa. Case report and review of the literature. Arch Intern Med. 1990;150(4):894-895.

48. Shinohara N, Nunoi K, Sato Y, Yoshinari M, Fujishima M. Repeated hypoglycemic coma in a patient with anorexia nervosa. Tonyobyo $J$ Jpn Diab Soc. 1994;37:759.

49. Smith J. Hypoglycaemic coma associated with anorexia nervosa. Aust N Z J Psychiatry. 1988;22(4):448-453.

50. Copeland PM, Herzog DB. Hypoglycaemia and death in anorexia nervosa. Psychother Psychosom. 1987;48(1-4):146-150.

51. Fonseca V, Ball S, Marks V, Havard CW. Hypoglycaemia associated with anorexia nervosa. Postgrad Med J. 1991;67(787): 460-461.

52. Ratclife PJ, Bevan JS. Severe hypoglycaemia and sudden death in anorexia nervosa. Psychol Med. 1985;15(3):679-681.

53. Yamada Y, Fushimi H, Inoue T, Nishinaka K, Kameyama M. Anorexia nervosa with recurrent hypoglycemic coma and cerebral hemorrhage. Intern Med. 1996;35(7):560-563.

54. Sakurai-Chin C, Ito N, Taguchi M, Miyakawa M, Takeshita A, Takeuchi Y. Hypoglycemic coma in a patient with anorexia nervosa coincident with acute exacerbation of liver injury induced by oral intake of nutrients. Intern Med. 2010;49(15):1553-1556.

55. Hadley SJ, Walsh BT. Gastrointestinal disturbances in anorexia nervosa and bulimia nervosa. Curr Drug Targets CNS Neurol Disord. 2003;2(1):1-9.

56. Turan M, Sen M, Canbay E, Karadayi K, Yildiz E. Gastric necrosis and perforation caused by acute gastric dilatation: report of a case. Surg Today. 2003;33(4):302-304.

57. Nakao A, Isozaki H, Iwagaki H, Kanagawa T, Takakura N, Tanaka N. Gastric perforation caused by a bulimic attack in an anorexia nervosa patient: report of a case. Surg Today. 2000;30(5):435-437.

58. Watanabe S, Terazawa K, Asari M, Matsubara K, Shiono H, Shimizu K. An autopsy case of sudden death due to acute gastric dilatation without rupture. Forensic Sci Int. 2008;180(2):e6-e10.

59. Tweed-Kent AM, Fagenholz PJ, Alam HB. Acute gastric dilatation in a patient with anorexia nervosa binge/purge subtype. J Emerg Trauma Shock. 2010;3(4):403-405.

60. Mathevon T, Rougier C, Ducher E, Pic D, Garcier JM, Schmidt J. Acute abdominal dilatation, a serious complication in the case of anorexia nervosa. Presse Med. 2004;33(9 Pt 1):601-603. French.

61. Sinicina I, Pankratz H, Büttner A, Mall G. Death due to neurogenic shock following gastric rupture in an anorexia nervosa patient. Forensic Sci Int. 2005;155(1):7-12.

62. Kim SC, Cho HJ, Kim MC, Ko YG. Sudden cardiac arrest due to acute gastric dilatation in a patient with an eating disorder. Emerg Med J. 2009;26(3):227-228. 
63. Bravender T, Story L. Massive binge eating, gastric dilatation and unsuccessful purging in a young woman with bulimia nervosa. JAdolesc Health. 2007;41(5):516-518.

64. Barada KA, Azar CR, Al-Kutoubi AO, et al. Massive gastric dilatation after a single binge in an anorectic woman. Int J Eat Disord. 2006;39(2): 166-169.

65. Willeke F, Riedl S, von Herbay A, Schmidt H, Hoffmann V, Stern J. Decompensated acute gastric dilatation caused by a bulimic attack in anorexia nervosa. Dtsch Med Wochenschr. 1996;121(40):1220-1225. German.

66. Adson DE, Mitchell JE, Trenkner SW. The superior mesenteric artery syndrome and acute gastric dilatation in eating disorders: a report of two cases and a review of the literature. Int J Eat Disord. 1997;21(2): 103-114.

67. Stheneur C, Rey C, Pariente D, Alvin P. Acute gastric dilatation with superior mesenteric artery syndrome in a young girl with anorexia nervosa. Arch Pediatr. 1995;2(10):973-976.

68. Takemura T, Iwamoto S, Tanigawa T, et al. Superior mesenteric artery syndrome in anorexia nervosa. A case report. Nihon Shokakibyo Gakkai Zasshi. 1988;85(4):939-943. Japanese.

69. Backett SA. Acute pancreatitis and gastric dilatation in a patient with anorexia nervosa. Postgrad Med J. 1985;61(711):39-40.

70. Abdu RA, Garritano D, Culver O. Acute gastric necrosis in anorexia nervosa and bulimia. Two case reports. Arch Surg. 1987;122(7):830-832.

71. Saul SH, Dekker A, Watson CG. Acute gastric dilatation with infarction and perforation. Report of fatal outcome in patient with anorexia nervosa. Gut. 1981;22(11):978-983.

72. Mehanna HM, Moledina J, Travis J. Refeeding syndrome: what it is, and how to prevent and treat it. BMJ. 2008;336(7659):1495-1498.

73. Veverbrants E, Arky RA. Effects of fasting and refeeding. I. Studies on sodium, potassium and water excretion on a constant electrolyte and fluid intake. J Clin Endocrinol Metab. 1969;29(1):55-62.

74. Barnhart JS Jr, Mittleman RE. Unusual deaths associated with polyphagia. Am J Forensic Med Pathol. 1986;7(1):30-34.

75. Murciano D, Rigaud D, Pingleton S, Armengaud MH, Melchior JC, Aubier M. Diaphragmatic function in severely malnourished patients with anorexia nervosa. Effects of renutrition. Am J Respir Crit Care Med. 1994;150(6 Pt 1):1569-1574.

76. Cariem AK, Lemmer ER, Adams MG, Winter TA, O’Keefe SJ. Severe hypophosphataemia in anorexia nervosa. Postgrad Med J. 1994;70(829):825-827.

77. Halmi KA. Physiology of anorexia nervosa and bulimia nervosa. In: Fairburn CG, Brownell KD, editors. Eating Disorders and Obesity: A Comprehensive Handbook. New York: Guiford Press; 2002: 267-271.

78. Friedman EJ. Death from ipecac intoxication in a patient with anorexia nervosa. Am J Psychiatry. 1984;141(5):702-703.

79. Silber TJ. Ipecac syrup abuse, morbidity, and mortality: isn't it time to repeal its over-the-counter status? J Adolesc Health. 2005;37(3): 256-260.
80. Yasuhara D, Naruo T, Taguchi S, Umekita Y, Yoshida H, Nozoe S. "End-stage kidney" in longstanding bulimia nervosa. Int J Eat Disord. 2005;38(4);383-385.

81. Wada S, Nagase T, Koike Y, Kugai N, Nagata N. A case of anorexia nervosa with acute renal failure induced by rhabdomyolysis; possible involvement of hypophosphatemia or phosphate depletion. Intern Med. 1992;31(4):478-482.

82. Neumärker KJ, Dudeck U, Meyer U, Neumärker U, Schultz E, Schönheit B. Anorexia nervosa and sudden death in childhood: clinical data and results obtained fron quantitative neurohistological investigations of cortical neurons. Eur Arch Psychiatry Clin Neurosci. 1997;247(1):16-22.

83. Bates T, Zlopasa O, Gasparović V. Anorexia nervosa: a life threatening condition. Lijec Vjesn. 2007;129(1-2):11-16. Article in Croatian.

84. Langlois NE. Sudden adult death. Forensic Sci Med Pathol. 2009;5(3): 210-232.

85. Backmund H, Mai N, Gerlinghoff M. Life-threatening complications and death in anorexia nervosa. Schweiz Arch Neurol Psychiatr. 1990;141(5):419-428. German

86. Lesinskiene S, Barkus A, Ranceva N, Dembinskas A. A meta-analysis of heart rate and QT interval alteration in anorexia nervosa. World $J$ Biol Psychiatry. 2008;9(2):86-91.

87. Takimoto Y, Yoshiuchi K, Kumano H, et al. QT interval and QT dispersion in eating disorders. Psychother Psychosom. 2004;73(5):324-328.

88. Miller KK, Grinspoon SK, Ciampa J, Hier J, Herzog D, Klibanski A. Medical findings in outpatients with anorexia nervosa. Arch Int Med. 2005;165:561-566.

89. Vázquez M, Olivares JL, Fleta J, Lacambra I, González M. Cardiac disorders in young women with anorexia nervosa. Rev Esp Cardiol. 2003;56(7):669-673. Spanish.

90. Ravaldi C, Vannacci A, Ricca V. Cardiac complications of anorexia nervosa. Recenti Prog Med. 2003;94(6):267-270. Italian.

91. Roche F, Barthélémy JC, Mayaud N, et al. Refeeding normalizes the QT rate dependence of female anorexic patients. Am J Cardiol. 2005;95(2): 277-280.

92. Ulger Z, Gürses D, Ozyurek AR, Arikan C, Levent E, Aydoğdu S. Follow-up of cardiac abnormalities in female adolescents with anorexia nervosa after refeeding. Acta Cardiol. 2006;61(1):43-49.

93. Lupoglazoff JM, Berkane N, Denjoy I, et al. Cardiac consequences of adolescent anorexia nervosa. Arch Mal Coeur Vaiss. 2001;94(5): 494-498.

94. Birmingham CL, Gritzner S. Heart failure in anorexia nervosa: case report and review of the literature. Eat Weight Disord. 2007;12(1):e7-e10.

95. Zalin AM, Lant AF. Anorexia nervosa presenting as reversible hypoglycaemic coma. J R Soc Med. 1984;77(3):193-195.

96. Arcelus J, Mitchell AJ, Wales J, Nielsen S. Mortality rates in patients with anorexia nervosa and other eating disorders. A meta-analysis of 36 studies. Arch Gen Psychiatry. 2011;68(7):724-731.

97. Roerig JL, Steffen KJ, Mitchell JE, Zunker C. Laxative abuse: epidemiology, diagnosis and management. Drugs. 2010;70(12):1487-1503.
Vascular Health and Risk Management

\section{Publish your work in this journal}

Vascular Health and Risk Management is an international, peerreviewed journal of therapeutics and risk management, focusing on concise rapid reporting of clinical studies on the processes involved in the maintenance of vascular health; the monitoring, prevention and treatment of vascular disease and its sequelae; and the involvement of

\section{Dovepress}

metabolic disorders, particularly diabetes. This journal is indexed on PubMed Central and MedLine. The manuscript management system is completely online and includes a very quick and fair peer-review system, which is all easy to use. Visit http://www.dovepress.com/ testimonials.php to read real quotes from published authors. 